\title{
Child maltreatment and adult living standards at 50 years
}

\author{
Authors: Snehal M Pinto Pereira PhD, Leah Li PhD, Chris Power PhD \\ Population, Policy and Practice, Great Ormond Street Institute of Child Health, University College \\ London, 30 Guilford Street, London WC1N 1EH.
}

Correspondence to: Prof Chris Power.

Fax: +44 (0)20 7905 2381. Telephone: +44 (0)207905 2106.

Email: christine.power@ucl.ac.uk

Address: as above.

Short title: Maltreatment and living standards at 50 years

Financial Disclosure: The authors have no financial relationships relevant to this article to disclose.

Funding source: This research was funded by the Department of Health Policy Research Programme through the Public Health Research Consortium (PHRC) and supported by the National Institute for Health Research Biomedical Research Centre at Great Ormond Street Hospital for Children NHS Foundation Trust and University College London. The views expressed in the publication are those of the authors and not necessarily those of the Department of Health. Information about the wider programme of the PHRC is available from http://phrc.lshtm.ac.uk. The funders had no input into study design; data collection, analysis, and interpretation; in the writing of the report; and in the decision to submit the article for publication. Researchers were independent of influence from study funders.

Potential Conflicts of Interest: The authors have no conflicts of interest relevant to this article to disclose.

Abbreviations: long-term sickness absence (LTS), not in employment, education or training (NEET), odds ratios (ORs)

What's known on this subject

Child maltreatment (abuse and neglect) has established effects on long-term mental health. The extent to which broader adult life circumstances (e.g. economic productivity) are affected and underlying child-to-adult pathways are less well understood due to scarcity of long-term follow-up.

What this study adds

Child maltreatment was associated with poor adult socioeconomic outcomes, with evidence of accumulating burden for those experiencing multiple maltreatments. Associations for neglect operated via cognition; associations for sexual and non-sexual abuse were little affected by adolescent cognition and mental health. 
Dr Pinto Pereira designed and conducted the research, performed statistical analysis, drafted the initial manuscript and approved the final manuscript as submitted.

Dr Li designed and conducted the research, reviewed and revised the manuscript and approved the final manuscript as submitted.

Prof Power designed and conducted the research, reviewed and revised the manuscript and approved the final manuscript as submitted.

Word count: 2998 


\section{Abstract (250/250 words)}

Background: Child maltreatment (abuse and neglect) has established effects on mental health. Less is known about its influence on adult economic circumstances. We aimed to establish associations of child maltreatment with such outcomes and explore potential pathways.

Methods: We used 1958 British birth cohort data $(\mathrm{N}=8,076)$ to examine associations of child neglect and abuse with adult (50y) long-term sickness absence (LTS), not in employment, education or training (NEET), lacking assets, income-related support, poor qualifications, financial insecurity, manual social class and social mobility. We assessed mediation of associations by 16y cognition and mental health.

Results: Abuse prevalence varied from 1\% (sexual) to $10 \%$ (psychological); $16 \%$ were neglected. $21 \%$ experienced one maltreatment type, $10 \%$ experienced $\geq 2$. Sexual and non-sexual abuse were associated with several outcomes e.g. for sexual abuse, $\mathrm{OR}_{\text {adjusted }}$ of income-related support was 1.75 $(1.12,2.72)$. Associations were little affected by potential mediating factors. Neglect was associated

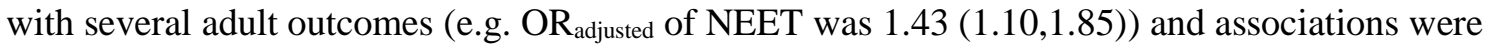
mediated by cognition and mental health (primarily by cognition): percent explained varied between $4 \%$ (NEET) to $70 \%$ (poor qualifications). In general, the risk of poor outcome increased by number of maltreatment types, e.g. $\mathrm{OR}_{\text {adjusted }}$ for LTS increased from 1.0 (reference) to $1.76(1.32,2.35)$ to 2.69 $(1.96,3.68)$ respectively for $0,1, \geq 2$ types of maltreatment.

Conclusions: Childhood maltreatment is associated with poor mid-adulthood socioeconomic outcomes, with accumulating risk for those experiencing multiple types of maltreatment. Cognitive ability and mental health are implicated in the pathway to outcome for neglect but not abuse. 


\section{Introduction}

Child maltreatment, encompassing abuse and neglect, is a major social-welfare problem. Several consequences have been identified including mental ill-health, obesity and poor cardiovascular profiles with effects perpetuating into adulthood ${ }^{1-4}$. Although early-life socioeconomic disadvantage is known to affect adult circumstances in terms of economic productivity, including employment, and social mobility ${ }^{5}$, less is known about the influence of maltreatment on such outcomes $^{3}$. Identifying influences on these outcomes is important, given their economic implications: e.g., costs of long-term absences from work are substantial and shared between individuals, employers and the State. Individuals suffer financial and social losses, becoming increasingly distanced from the labour market; UK employers pay $£ 9 \mathrm{bn} /$ year in sick-pay associated costs; the State spends $£ 13 \mathrm{bn} /$ year on health-related benefits ${ }^{6}$. Therefore, reducing unfavourable outcomes is high on the policy agenda ${ }^{6,7}$.

The limited evidence available on associations between child maltreatment and adult socioeconomic outcomes comes from cross-sectional studies ${ }^{8,9}$ or includes maltreatment cases that have been reported to authorities, which may be atypical of maltreatment in the general population ${ }^{10}$. Moreover, because child maltreatment is associated with poorer educational achievement and $\operatorname{cognition}^{3,11}$, we might expect less favourable social mobility patterns from class of origin, as well as less advancement over the individuals' working life. The deficits in cognitive abilities and behavioural adjustment observed in maltreated children ${ }^{11}$ could represent important pathways to reduced economic circumstances in adulthood, given that such deficits have detrimental economic consequences $^{12-14}$. It is important to improve understanding of the full consequences of child maltreatment and likely explanations, partly because detrimental socioeconomic outcomes have implications for health ${ }^{15-18}$ yet, to our knowledge, such associations have not been demonstrated.

Using a general population birth cohort, we aimed to establish the extent to which child maltreatment is associated with adult circumstances in respect of labour market participation, living standards and social mobility, taking account of other early-life factors such as parental education. We 
also examined potential mediating pathways via adolescent cognition and mental health. Specific outcomes included: long-term sickness absence; not in employment, education or training; lacking assets; income-related support; poor educational qualifications; financial insecurity; manual social class and inter- and intra-generational social mobility to mid-adulthood. We examined neglect and (different types of) abuse separately to assess whether there were differential effects on outcomes and also examined associations for multiple types of maltreatment to assess cumulative burden.

\section{Methods}

The 1958 British birth cohort is a longitudinal study of all born in one week, March 1958, across England, Scotland and Wales $(n=17,638)$ and 920 immigrants with the same birth week ${ }^{19}$. Information was collected throughout childhood (birth, $7,11,16 \mathrm{y})$ and adulthood $(23,33,42,45,50 \mathrm{y})$ from individuals, as well as parents, teachers and school doctors (childhood surveys) and nurses (at 45y). Of 11,971 invited, 9,377 participated in the 45y survey, with 9,315 completing childhood maltreatment questions; of these, 8150 participated at 50y (Supplementary Figure 1). Respondents in mid-adulthood were broadly representative of the surviving cohort ${ }^{20}$. Ethical approval was given for various surveys, including at 50y by the London Multi-centre Research Ethics Committee; informed consent was obtained from participants at various ages.

Childhood maltreatment: Neglect (prospective) was identified from information collected in childhood from parental interviews (usually the mother) and the child's teacher, using structured questionnaires (Table 1). Emotional neglect and abuse (sexual, physical, psychological or witnessing) to $16 \mathrm{y}$ were reported at $45 \mathrm{y}$ using a confidential direct computer data entry questionnaire (CASI) (Table 1).

Adult outcomes: Details are given in Table 2. In brief, we identified three labour market groups from participant reports of their current economic activity: the (i) long-term sick (LTS) (ii) not in employment, education or training (NEET) and (iii) employed (full or part-time as an employee or self-employed) or in education or training. Home ownership and receipt of income-related support were used as markers of assets/wealth. Education level was measured prospectively to $50 \mathrm{y}$. At $45 \mathrm{y}$, 
information on financial insecurity was ascertained. For social class and mobility, we used information on occupation collected at birth, $23 \mathrm{y}$ and $50 \mathrm{y}$ to group non-manual and manual classes. Social mobility was examined from (i) parent's class to own class at 50y (inter-generational) and (ii) own class at $23 y$ to $50 y$ (intra-generational). For inter-generational mobility we created two binary variables: (i) upward mobility from manual class at birth (vs stable manual); and (ii) downward mobility from non-manual class at birth (vs stable non-manual). Similar variables were created for intra-generational mobility (23-50y).

Covariates were identified as early-life factors that influence socioeconomic destinations and included those related to socioeconomic background (i.e. social class in 1958, parental education, household amenities, crowding and tenure), birth (maternal age, birthweight, birth order) and child ill-health. Potential mediating factors include cognitive ability and mental health assessed at 16y (indicated by reading/maths tests and internalizing/externalising behaviours respectively, as in previous work ${ }^{11}$ ).

\section{Analysis}

We used logistic regression to assess associations of each type of maltreatment with adult outcomes (labour market participation, living standards and social class) separately. We tested the interaction between each type of maltreatment and sex; there was little evidence of effect modification, hence results are presented for sexes combined. We examined univariable associations before adjusting for covariates (listed above). Next, because different types of maltreatment cooccur $^{21}$, we assessed (i) associations for all types of maltreatment simultaneously and (ii) two-way correlations between maltreatment types. Mutual adjustment for six types of maltreatment may be over-adjustment. Thus, we derived a score to represent the number of moderately correlated types of maltreatment (i.e. pairwise correlation coefficients $\geq 0.4$ ) and examined the score and other types of maltreatment simultaneously with outcomes. To assess possible mediation of associations by cognition and mental health we used two methods in which these factors were modelled separately and combined: (i) in a series of adjusted models; and (ii) in mediation analyses using inverse odds ratio weighting ${ }^{22}$ from which we obtained 'total effects' of maltreatment on outcomes and 'direct 
effects' that were not via potential mediator(s) (percent of 'total effect' explained was calculated). To investigate cumulative burden of multiple types of maltreatment, we examined associations between number of types $(0,1, \geq 2)$ and outcomes using a trend test.

In sensitivity analyses we checked, first whether child maltreatment associations with adult (50y) outcomes were replicated with similar outcomes, where available, at 23y, i.e. LTS, NEET and social class. Second, we examined associations for NEET as two categories: unemployed seeking work and looking after home/family. Associations with outcomes were broadly similar for the two categories (data not shown) possibly because individuals may identify as home/family rather than unemployed, thus associations for combined NEET groups are presented.

To investigate whether those maltreated in childhood were as likely as the non-maltreated to be socially mobile, we estimated odds ratios (ORs) for upward and downward mobility from class at birth (inter-generational mobility). Specifically, we examined upward mobility among those who were from a manual background and downward mobility among those from a non-manual class. Similar analyses were undertaken for intra-generational mobility.

Of 8,150 participants completing the child maltreatment questions at $45 \mathrm{y}$ and participating at $50 \mathrm{y}$, the number available for analysis was 8,076 due to exclusions $n=98$ with intellectual impairment assessed at $7 \mathrm{y}$ and missing data $(\mathrm{n}=5)$ (Supplementary Figure 1). Social class and mobility analyses were restricted to those employed at 50y $(\mathrm{n}=7,002)$. Missing data ranged from $0.01 \%$ (education level) to $16 \%$ (23y social class). To minimize data loss, missing data were imputed using multiple imputation chained equations. Following guidelines (to justify the plausibility of the missing at random assumption) imputation models included all model variables (including 23y outcomes), plus main predictors of missingness ( $7 \mathrm{y}$ behaviour and cognitive ability $)^{20}$. Regression analyses were run across 20 imputed datasets and overall estimates were obtained. Imputed results were broadly similar to those using observed values; the former are presented.

\section{Results}


Prevalence of child maltreatment varied from $1 \%$ for sexual abuse, $6 \%$ for physical and witnessing abuse, to $10 \%$ for psychological abuse; $11 \%$ for emotional neglect and $16 \%$ were identified as neglected (prospective) (Table 3). In mid-adulthood, outcomes such as LTS, NEET and financial insecurity affected $<1$ in 10 of the population, while outcomes such as income-related support were more prevalent. Upward mobility from class of origin was common (44\%), partly occurring as intra-generational mobility, $23 \mathrm{y}$ to $50 \mathrm{y}$.

All types of child maltreatment, when examined separately, were associated with increased risk of adult LTS, NEET, lacking assets and financial insecurity (Supplementary Table (ST) 1, Model 1). Associations attenuated after adjustment for covariates (Model 2); e.g., OR of LTS from 2.50(95\% CI: $1.94,3.22)$ to $1.77(1.34,2.33)$ for neglect (prospective). For LTS, NEET and social class at 23y patterns of association were similar to those observed for 50y outcomes (ST2). 21\% of the population experienced one type of maltreatment; $10 \%$ experienced $\geq 2$ (ST3). Except for qualifications and social class, the risk of unfavourable outcome increased with number of types of maltreatment e.g. $\mathrm{OR}_{\text {adjusted }}$ for LTS increased from 1.0 to $1.76(1.32,2.35)$ to $2.69(1.96,3.68)$ ( $\mathrm{p}_{\text {trend }}<0.01$ ) for 0,1 and $\geq 2$ types respectively.

When all maltreatment types were considered simultaneously (ST1, Model 3) associations with 50y outcomes were reduced, particularly for emotional neglect, physical, psychological and witnessing abuse. These three types of abuse were moderately correlated ( $r \geq 0.4)$, whilst other types of maltreatment were less correlated $(r<0.3)$; hence we created a non-sexual abuse score $(0,1,2-3)$. In simultaneous analysis of neglect (prospective), emotional neglect, sexual and non-sexual abuse, both abuse measures were associated with lacking assets, income-related support and financial insecurity (Table 4). Sexual abuse was also associated with poor qualifications and manual class, while nonsexual abuse was associated with LTS: the OR increased from 1.0(reference) to $1.75(1.22,2.51)$ to $2.10(1.40,3.17)\left(\mathrm{p}_{\text {trend }}<0.01\right)$ respectively for 0,1 and 2-3 types. For both abuse measures, associations with outcomes were generally little affected by cognition and mental health at 16y (Table 4; ST4). Emotional neglect was associated with only one outcome (financial insecurity) and again, 16y cognitive ability and mental health did not explain the association. Lastly, neglect (prospective) was 
associated with several outcomes (LTS, NEET, lacking assets, poor qualifications and manual class), e.g., the OR of LTS was 1.69(1.28,2.23) and for NEET was 1.43(1.10,1.85). Associations were attenuated or abolished when cognition and mental health were included in models (Table 4) or considered as mediators (ST4). Hence, associations were mediated by these factors, with percent explained varying from $4 \%$ (NEET) to $70 \%$ (poor qualifications); in separate models for each mediator, the effect was mostly via cognition (percent explained range: $8 \%$ to $67 \%$, data not shown).

Neglect (prospective) and sexual abuse were associated with social mobility (Table 5). These groups were less likely to be upwardly mobile (move from manual to non-manual class) both between and within generations (e.g. neglect (prospective) OR: $0.45(0.39,0.53)$ and $0.61(0.50,0.74)$ respectively). The neglected (prospective) were also more likely to be downwardly mobile (move from non-manual to manual class) between and within generations (OR: 2.31(1.56,3.41) and 2.11(1.63,2.74)). No clear social mobility patterns were found for non-sexual abuse.

\section{Discussion}

In this population based study of child maltreatment and adult socioeconomic outcomes, we showed two important findings. First, there were long-term associations of childhood abuse and neglect with unfavourable outcomes in mid-adulthood across a range of important socioeconomic indicators such as LTS and lacking assets. Associations were mostly robust after adjustment for other early-life factors including social class and parental education, and risk of unfavourable outcomes increased with multiple types of maltreatment. Second, our study elucidates on some important mechanisms underlying the child maltreatment-adult outcome associations by showing that adolescent cognitive ability had a predominant mediating role in neglect (prospective) associations with several adult outcomes, whilst cognition and mental health had negligible mediating effects for sexual and non-sexual abuse associations.

Our study has several strengths including prospectively measured mediating factors and a range of socioeconomic outcomes. Potential confounding factors were also recorded prospectively, 
e.g., family socioeconomic background (parental education, household tenure). We cannot exclude the possibility of residual or uncontrolled confounding (e.g. through inadequate measurement of relevant factors e.g. parental cognitive capacities). Ascertainment of childhood maltreatment is not straightforward with limitations noted for all methods ${ }^{3}$, including those used here. Our neglect measure has the advantage of prospective ascertainment of some (failure to meet a child's basic physical, emotional or educational needs) but not all aspects (e.g. inadequate nutrition) of the conventional definition ${ }^{3}$. Multiple sources for neglect reporting (parent and teacher) may reduce misclassification ${ }^{23}$ and rather than relying on individual items, we used a composite score. Abuse by a parent to 16y was reported in adulthood; exclusion of abuse by others may lead to an under-estimate of prevalence and information is lacking on timing, frequency, and duration of abuse. Despite differences in study design, prevalence was generally within ranges reported in a review ${ }^{3}$ and similar to another UK study ${ }^{24}$. Study power to detect associations with sexual abuse was limited, due to the few reported cases. Retrospective reports are common due to the lack of reliable alternative methods ${ }^{3}$, but concerns remain about validity ${ }^{25}$ e.g. biases from rationalizing economic under-achievement ${ }^{26}$. In this regard, our sensitivity analyses replicating associations for outcomes two decades prior to retrospective reports suggests that such biases are unlikely to be a major explanation for associations. Construct validity of retrospective reports is suggested by previous work showing expected associations with prospectively assessed family dysfunction ${ }^{27}$ and mental ill-health ${ }^{11}$. Reported abuse was blind to knowledge of research questions and most mid-adult outcomes (6 of 7) were assessed 5y later (age 50y). Participants in mid-adulthood are generally representative of the surviving cohort $^{20}$; we followed current guidelines for multiple imputation ${ }^{28}$ to avoid loss from missing data.

Our study demonstrates associations for a breadth of maltreatments and adult outcomes measured decades later in mid-adulthood. The range of outcomes is important because there is no single measure of socioeconomic position; indicators reflect different, although often related, characteristics $^{29}$ that may have specific limitations, e.g. housing varies over time and geographically. The outcomes are important because of their costs to individuals and society: e.g., in Britain approximately 140 million working days/year are lost from sickness absence ${ }^{6} ; 1.68$ million are 
unemployed $^{30}$. LTS is associated with premature mortality ${ }^{15-17}$; worklessness with physical and mental ill-health ${ }^{18}$ and with educational and economic outcomes in subsequent generations ${ }^{31}$. Therefore reduction of LTS absence and worklessness are policy priorities ${ }^{6,7}$. The timing of outcomes is also noteworthy: previous studies have examined socioeconomic outcomes in early adulthood ${ }^{32}$ or mixed age samples ${ }^{8,9}$, our findings for both early and later adulthood outcomes suggests that the impact of childhood maltreatment persists over decades. To our knowledge this has not been demonstrated previously. Age 50y is close to peak earning capacity in the $\mathrm{UK}^{33}$; poor outcomes at this age, e.g. lacking assets, may presage hardship and associated ill-health during old age. Patterns of association were generally consistent across maltreatments, and when multiple types were examined cumulatively, the greatest maltreatment burden was associated with greatest risk of unfavourable outcome. Findings for LTS and NEET are consistent with other studies showing that greater exposure to adverse childhood experiences is linked to inability to work $^{8}$ and unemployment ${ }^{8,9}$ in US mixed age samples. The observed magnitude of maltreatment—outcome associations is not negligible, when compared to other influences: ORs for LTS varied between 1.4 to 2.3 for different maltreatments versus 2.2 reported for depression ${ }^{34}$. With few exceptions ${ }^{9}$ previous studies examine single (e.g. sexual abuse $\mathrm{s}^{32,35}$ ) or combined maltreatments without examining potential differential effects ${ }^{8}$. Nevertheless, our findings generally agree with the literature ${ }^{10,32,35,36}$, thereby adding credence to the growing evidence (especially given differences in maltreatment ascertainment methods). For example, the detrimental maltreatment associations with education, employment and assets in our general population agree with those for documented (i.e. more extreme) maltreatment ${ }^{10}$. Our witnessing abuse findings are novel; to our knowledge, this has not been examined, although witnessing parental violence has been associated with lower adult income ${ }^{36}$. However, not all findings are consistent, e.g., sexual abuse and education associations shown here agree with some ${ }^{37}$ but not all ${ }^{32}$ studies and sex differences $^{10,35}$ in associations were not replicated. Child neglect and sexual abuse but no other maltreatments were associated with later social class and interestingly, these groups were less likely to be upwardly mobile across and within generations. Findings are consistent with more general observations on disadvantaged groups having less favourable mobility patterns; they are important given policy commitments to lowering poverty and increasing social mobility ${ }^{38}$. 
With regard to potential mechanisms underlying child maltreatment-adult outcome associations, we found support for mediating effects of adolescent cognitive abilities and mental health in associations for neglect (prospective) where a predominant effect was observed for cognition. Such findings are as expected from evidence of deficits in cognitive abilities and behavioural adjustment among maltreated children ${ }^{11}$, and the detrimental economic consequences related to these deficits ${ }^{12-14}$. This finding argues for support for remedial inputs to cognitive skills and development of children who have been neglected, which may involve clinicians, child welfare and other practitioners. Intriguingly, our results provide little support for mediating effects of adolescent cognitive abilities or behavioural adjustment in the associations for sexual and non-sexual abuse. Explanations for this unexpected finding are not clear. Our cognitive and behavioural measures were prospectively assessed and of demonstrable relevance to neglect associations, but may not capture the most salient dimensions for abuse. Given these findings and the scarcity of other studies on potential mechanisms, our study highlights the need for future research to confirm our results and to investigate additional mechanisms. This research is warranted to inform the direction of effective remedial strategies.

In conclusion, childhood abuse and neglect have long-term associations with detrimental outcomes in mid-adulthood, indicated by a range of socioeconomic measures. Risk of unfavourable outcome(s) was increased for those experiencing multiple types of maltreatment. Our findings suggest that the maltreated grow-up to experience socioeconomic disadvantage, which in turn may affect their health and that of the next generation. Our study therefore contributes to the evidence base on the full long-term costs of child maltreatment, elucidation of which is important to determine policy priorities. Prevention of maltreatment is a primary goal but represents an enormous challenge for which continued efforts are essential. In addition, investment in programmes to alleviate the ill-effects of maltreatment is needed. Our study suggests that one important target for action is the maximisation of cognitive skills and development of neglected children. 
Acknowledgements: The authors are grateful to the Centre for Longitudinal Studies (CLS), UCL Institute of Education for the use of these data and to the UK Data Service for making them available. However, neither CLS nor the UK Data Service bear any responsibility for the analysis or interpretation of these data. 


\section{References}

1. Clark C, Caldwell T, Power C, Stansfeld SA. Does the influence of childhood adversity on psychopathology persist across the lifecourse? A 45-Year prospective epidemiologic study. Ann. Epidemiol. May 2010;20(5):385-394.

2. Norman RE, Byambaa M, De R, Butchart A, Scott J, Vos T. The long-term health consequences of child physical abuse, emotional abuse, and neglect: A systematic review and meta-analysis. PloS Med. Nov 2012;9(11).

3. Gilbert R, Widom CS, Browne K, Fergusson D, Webb E, Janson S. Child maltreatment 1 Burden and consequences of child maltreatment in high-income countries. Lancet. Jan 3 2009;373(9657):68-81.

4. Power C, Pinto Pereira SM, Li L. Childhood maltreatment and BMI trajectories to mid-adult life: Follow-up to age 50y in a British birth cohort. Plos One. 2015;10(3):e0119985.

5. McKnight A. Downward mobility, opportunity hoarding and the 'glass floor'. London: Social Mobility and Child Poverty Commission; 2015.

6. Black C, Frost D. Health at work-an independent review of sickness absence. London: Department for Work and Pensions; 2011.

7. State of the nation report: Poverty, worklessness and welfare dependency in the UK. London: Cabinet Office; 2010.

8. Liu Y, Croft JB, Chapman DP, et al. Relationship between adverse childhood experiences and unemployment among adults from five US states. Soc. Psychiatry Psychiatr. Epidemiol. Mar 2013;48(3):357-369.

9. Zielinski DS. Child maltreatment and adult socioeconomic well-being. Child Abuse Negl. Oct 2009;33(10):666-678.

10. Currie J, Widom CS. Long-term consequences of child abuse and neglect on adult economic well-being. Child Maltreatment. May 2010;15(2):111-120.

11. Geoffroy MC, Pinto Pereira SM, Li L, Power C. Child neglect and maltreatment and childhood-to-adulthood cognition and mental health in a prospective birth cohort. J. Am. Acad. Child Adolesc. Psychiatry. Jan 2016;55(1):33-40.

12. Richards $M$, Power $C$, Sacker $A$. Paths to literacy and numeracy problems: evidence from two British birth cohorts. J. Epidemiol. Community Health. Mar 2009;63(3):239-244.

13. Kessler RC. The costs of depression. Psychiatr. Clin. North Am. Mar 2012;35(1):1-14.

14. Goodman A, Joyce R, Smith JP. The long shadow cast by childhood physical and mental problems on adult life. Proc. Natl. Acad. Sci. U. S. A. Apr 12 2011;108(15):6032-6037.

15. Head J, Ferrie JE, Alexanderson K, Westerlund H, Vahtera J, Kivimaki M. Diagnosis-specific sickness absence as a predictor of mortality: The Whitehall II prospective cohort study. BMJ. Oct 11 2008;337(7674).

16. Vahtera J, Pentti J, Kivimaki M. Sickness absence as a predictor of mortality among male and female employees. J. Epidemiol. Community Health. Apr 2004;58(4):321-326.

17. Gjesdal S, Ringdal PR, Haug K, Maeland JG, Vollset SE, Alexanderson K. Mortality after longterm sickness absence: Prospective cohort study. Eur J Public Health. Oct 2008;18(5):517-

521.

18. Waddell G, Burton AK. Is work good for your health and well-being?: The Stationery Office; 2006.

19. Power C, Elliott J. Cohort profile: 1958 British birth cohort (National Child Development Study). Int. J. Epidemiol. 2006;35(1):34-41.

20. Atherton K, Fuller E, Shepherd P, Strachan DP, Power C. Loss and representativeness in a biomedical survey at age 45 years: 1958 British birth cohort. J. Epidemiol. Community Health. Mar 2008;62(3):216-223.

21. Dong $M$, Anda RF, Felitti VJ, et al. The interrelatedness of multiple forms of childhood abuse, neglect, and household dysfunction. Child Abuse Negl. Jul 2004;28(7):771-784. 
22. Nguyen QC, Osypuk TL, Schmidt NM, Glymour MM, Tchetgen EJT. Practical Guidance for Conducting Mediation Analysis With Multiple Mediators Using Inverse Odds Ratio Weighting. Am. J. Epidemiol. Mar 1 2015;181(5):349-356.

23. Kendall-Tackett $\mathrm{K}$, Becker-Blease $\mathrm{K}$. The importance of retrospective findings in child maltreatment research. Child Abuse Negl. Jul 2004;28(7):723-727.

24. May-Chahal C, Cawson P. Measuring child maltreatment in the United Kingdom: A study of the prevalence of child abuse and neglect. Child Abuse Negl. Sep 2005;29(9):969-984.

25. Widom CS, Raphael KG, DuMont KA. The case for prospective longitudinal studies in child maltreatment research: commentary on Dube, Williamson, Thompson, Felitti, and Anda (2004). Child Abuse Negl. Jul 2004;28(7):715-722.

26. Widom CS, Weiler BL, Cottler LB. Childhood victimization and drug abuse: a comparison of prospective and retrospective findings. J. Consult. Clin. Psychol. Dec 1999;67(6):867-880.

27. Denholm R, Power C, Thomas $C$, Thomas $C$. Child maltreatment and household dysfunction in a British birth cohort. Child Abuse Rev. Sep 2013;22(5):340-353.

28. Sterne JA, White IR, Carlin JB, et al. Multiple imputation for missing data in epidemiological and clinical research: Potential and pitfalls. BMJ. 2009;338:b2393.

29. Galobardes B, Shaw M, Lawlor DA, Lynch JW, Smith GD. Indicators of socioeconomic position (part 1). J. Epidemiol. Community Health. Jan 2006;60(1):7-12.

30. UK Labour Market, January 2016: Office for National Statistics; 2016.

31. Schoon I, Barnes M, Brown V, Parsons S, Ross A, Vignoles A. Intergenerational transmission of worklessness: Evidence from the Millennium Cohort and the Longitudinal Study of Young People In England. Vol Research Report DFE-RR234. London: Department for Education; 2012.

32. Fergusson DM, McLeod GFH, Horwood LJ. Childhood sexual abuse and adult developmental outcomes: Findings from a 30-year longitudinal study in New Zealand. Child Abuse Negl. Sep 2013;37(9):664-674.

33. Annual Survey of Hours and Earnings 2015, Provisional Results: Office for National Statistics; 2015.

34. Henderson $\mathrm{M}$, Clark $\mathrm{C}$, Stansfeld $\mathrm{S}$, Hotopf M. A lifecourse approach to long-term sickness absence-A cohort study. Plos One. May 3 2012;7(5).

35. Barrett A, Kamiya $Y$, Sullivan VO. Childhood sexual abuse and later-life economic consequences. J Behav Exp Econ. Dec 2014;53:10-16.

36. Covey HC, Menard S, Franzese RJ. Effects of adolescent physical abuse, exposure to neighborhood violence, and witnessing parental violence on adult socioeconomic status. Child Maltreatment. May 2013;18(2):85-97.

37. Noll JG, Shenk CE, Yeh MT, Ji J, Putnam FW, Trickett PK. Receptive language and educational attainment for sexually abused females. Pediatrics. Sep 2010;126(3):e615-622.

38. State of the Nation 2015: Social mobility and child poverty in Great Britain: Social mobility and child poverty commission; 2015.

39. Rosenman S, Rodgers B. Childhood adversity in an Australian population. Soc. Psychiatry Psychiatr. Epidemiol. 2004;39(9):695-702.

40. Parker G. Parental characteristics in relation to depressive disorders. Br. J. Psychiatry. February 1, 1979 1979;134(2):138-147.

41. Rodgers B. Reported parental behaviour and adult affective symptoms. 1. Associations and moderating factors. Psychol. Med. 1996;26(01):51-61.

42. Riso LP, Miyatake RK, Thase ME. The search for determinants of chronic depression: a review of six factors. J. Affect. Disord. 2002;70(2):103-115.

43. Rutter M. A children's behaviour questionnaire for completion by teachers: preliminary findings. Journal of Child Psychology and Psychiatry. 1967;8(1):1-11. 
Table 1: Definition of child maltreatment and representative variables from the 1958 British birth cohort.

\begin{tabular}{|c|c|c|c|c|}
\hline & Definition $^{3}$ & $\begin{array}{l}1958 \text { British birth cohort } \\
\text { variables* }\end{array}$ & $\begin{array}{l}\text { Reference } \\
\text { age }\end{array}$ & $\begin{array}{l}\text { Age collected } \\
\text { (Ascertainment } \\
\text { method } ¥ \text { ) }\end{array}$ \\
\hline \multirow[t]{5}{*}{$\begin{array}{l}\text { Neglect } \\
\text { (prospective) } f\end{array}$} & \multirow{7}{*}{$\begin{array}{l}\text { Failure to meet a child's basic physical, } \\
\text { emotional, medical/dental, or education } \\
\text { need; failure to provide adequate nutrition, } \\
\text { hygiene, or shelter; or failure to ensure a } \\
\text { child's safety }\end{array}$} & $\begin{array}{l}\text { constructed from: } \\
\text { - child looks undernourished, } \\
\text { scruffy or dirty }\end{array}$ & $7 y$ and $11 y$ & 7 and $11 \mathrm{y}(\mathrm{T})$ \\
\hline & & $\begin{array}{l}\text { - hardly ever takes outings with } \\
\text { mother }\end{array}$ & $7 y$ and $11 y$ & 7 and $11 y(P)$ \\
\hline & & $\begin{array}{l}\text { - hardly ever takes outings with } \\
\text { father }\end{array}$ & $7 y$ and $11 y$ & 7 and $11 y(P)$ \\
\hline & & $\begin{array}{l}\text { - mother has little interest in } \\
\text { education }\end{array}$ & $7 y$ and $11 y$ & 7 and $11 \mathrm{y}(\mathrm{T})$ \\
\hline & & $\begin{array}{l}\text { - father has little interest in } \\
\text { education }\end{array}$ & $7 y$ and $11 y$ & 7 and $11 \mathrm{y}(\mathrm{T})$ \\
\hline \multirow[t]{2}{*}{$\begin{array}{l}\text { Emotional } \\
\text { neglect } \chi\end{array}$} & & $\begin{array}{l}\text { constructed from: } \\
\text { - how affectionate was your } \\
\text { mother towards you? }\end{array}$ & $0-16 y$ & $45 y(S)$ \\
\hline & & $\begin{array}{l}\text { - how affectionate was your father } \\
\text { towards you? }\end{array}$ & $0-16 y$ & $45 y(S)$ \\
\hline Sexual abuse & $\begin{array}{l}\text { Any completed or attempted sexual act, } \\
\text { sexual contact, or non-contact sexual } \\
\text { interaction with a child by a caregiver. }\end{array}$ & I was sexually abused by a parent & $0-16 y$ & $45 y(S)$ \\
\hline $\begin{array}{l}\text { Physical } \\
\text { abuse }\end{array}$ & $\begin{array}{l}\text { Intentional use of physical force or } \\
\text { implements against a child that results in, or } \\
\text { has the potential to result in, physical } \\
\text { injury. }\end{array}$ & $\begin{array}{l}\text { - I was physically abused by a } \\
\text { parent - punched, kicked or hit } \\
\text { or beaten with an object, or } \\
\text { needed medical treatment }\end{array}$ & $0-16 y$ & $45 y(S)$ \\
\hline
\end{tabular}


Psychological Intentional behaviour that conveys to a

abuse

child that $\mathrm{h} / \mathrm{she}$ is worthless, flawed,

unloved, unwanted, endangered, or valued

only in meeting another's needs.

UK definition includes harmful

(unintentional) parent-child interactions:

'the persistent emotional ill-treatment of a

child such as to cause severe and persistent

adverse effects on the child's emotional

development'
- I was verbally abused by a parent

$0-16 y$

$45 y(S)$

- I suffered humiliation, ridicule, bullying or mental cruelty from a parent
Witnessing
Any incident of threatening behaviour,
intimate violence, or abuse (psychological, physical, sexual, financial, or emotional) between
intimate partners or adult family members,

- I witnessed physical or sexual

$0-16 y$

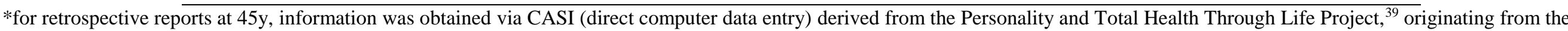

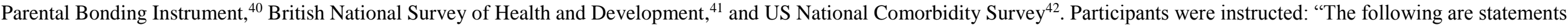
about your childhood. For each, please say whether the statement applies to you." Response options were: "Yes", "No", "Can't say".

$¥(\mathrm{~S})$ : self-report; $(\mathrm{T})$ : teacher-report; $(\mathrm{P})$ : parent-report

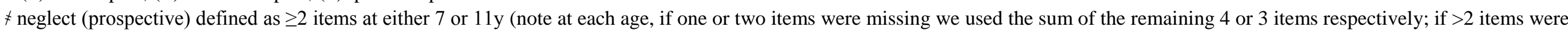
missing, we treated neglect as missing)

$\chi$ defined as either parent 'not at all affectionate towards me' 
Table 2: Details of outcomes (adult socio-economic conditions), covariates and potential mediating factors

\begin{tabular}{|c|c|c|}
\hline $\begin{array}{l}\text { Adult socio- } \\
\text { economic } \\
\text { outcomes }\end{array}$ & $\begin{array}{l}\text { Age } \\
\text { (ascertainment } \\
\text { method*) }^{*}\end{array}$ & Details \\
\hline $\begin{array}{l}\text { Long-term sick } \\
\text { (LTS) }\end{array}$ & $23 y, 50 y(S)$ & $\begin{array}{l}\text { current economic activity: sickness absence (23y); permanently } \\
\text { sick/disabled (50y) }\end{array}$ \\
\hline $\begin{array}{l}\text { Not in } \\
\text { employment, } \\
\text { education or } \\
\text { training (NEET) }\end{array}$ & $23 y, 50 y(S)$ & $\begin{array}{l}\text { current economic activity: unemployed and seeking work or looking after } \\
\text { the home or family }\end{array}$ \\
\hline Lack of assets & $50 y(S)$ & current status: non-home owner \\
\hline $\begin{array}{l}\text { Income-related } \\
\text { support }\end{array}$ & $50 \mathrm{y}(\mathrm{S})$ & $\begin{array}{l}\text { currently in receipt of } \geq 1 \text { targeted benefit or tax credit including: housing } \\
\text { benefit, council tax benefit, jobseekers allowance, income support, } \\
\text { working tax credit and child tax credit (universal credits such as child } \\
\text { benefit were excluded) }\end{array}$ \\
\hline Financial & $45 \mathrm{y}(\mathrm{S})$ & $\begin{array}{l}\text { affirmative answer to 'during the last six months have you had a major } \\
\text { financial crisis?' }\end{array}$ \\
\hline Poor qualifications & up to $50 \mathrm{y}(\mathrm{S})$ & $<$ O-levels (broadly comparable to < grade 10 in the US) \\
\hline $\begin{array}{l}\text { Manual social } \\
\text { class }\end{array}$ & $23 \mathrm{y}, 50 \mathrm{y}(\mathrm{S}) * *$ & $\begin{array}{l}\text { current occupation coded according to the registrar general's social } \\
\text { classification (a standard method of categorising occupations in the UK) } \\
\text { and categorised as non-manual (professional/managerial, skilled non- } \\
\text { manual) or manual (skilled manual, partly skilled/unskilled) }\end{array}$ \\
\hline \multicolumn{3}{|r|}{ 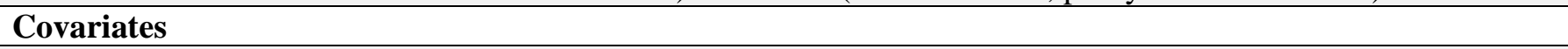 } \\
\hline Maternal age & Birth (P) & age (years) at birth of cohort member in 1958 \\
\hline Birthweight & Birth (M) & $\mathrm{kg}$ \\
\hline Birth order & $7 y(P)$ & $1,2,3,4+$ \\
\hline $\begin{array}{l}\text { Childhood ill } \\
\text { health }\end{array}$ & $7 y(P)$ & child has any physical handicap or disabling condition \\
\hline $\begin{array}{l}\text { Social class in } \\
1958\end{array}$ & Birth (P) & $\begin{array}{l}\text { father's occupation categorised as: professional/managerial, skilled non- } \\
\text { manual, skilled manual, partly skilled/unskilled/no male head }\end{array}$ \\
\hline Parental education & Birth and 7y (P) & both mother and father left school at the minimum leaving age \\
\hline $\begin{array}{l}\text { Household } \\
\text { amenities }\end{array}$ & $7 y(P)$ & lack of or sharing a bathroom, lavatory or hot water \\
\hline $\begin{array}{l}\text { Household } \\
\text { crowding }\end{array}$ & $7 y(P)$ & $>1$ person per room \\
\hline Housing tenure & $7 y(P)$ & owner occupier, renter or other \\
\hline
\end{tabular}

\section{Potential mediating factors}

Cognitive ability $16 \mathrm{y}(\mathrm{M})$

Reading (selection of appropriate words to complete 35 sentences, parallel to the Watts Vernon Comprehension test) and mathematics (numerical and geometric questions with 27 multiple choice questions and 4 true-or-false questions) tests, administered at school. Tests were conducted over several months and were age standardized to $16 \mathrm{y}$. The two scores were converted to a scale of 0 to 100 and averaged. Examined as one internally standardized $\mathrm{z}$ score (mean $=0, \mathrm{SD}=1)^{11}$.

Mental health $16 \mathrm{y}(\mathrm{T})$

Internalising and externalising behaviours on the Rutter Scale ${ }^{43}$.

Examined as two internally standardized $\mathrm{z}$ scores (mean $=0, \mathrm{SD}=1$ ).

*(S): self-report; (P): parent-report; $(\mathrm{T})$ teacher-report; $(\mathrm{M})$ measured or tests

**social mobility was an additional outcome, using parent report at birth and self-report at $23 \mathrm{y}$ and $50 \mathrm{y}$ 
Table 3: Prevalence of childhood maltreatment, adult labour market participation, living standards social class and mobility in the 1958 birth cohort ( $\mathrm{N}=3,947$ males; 4,129 females)

\begin{tabular}{|c|c|c|c|c|}
\hline & Males & Females & Total & \\
\hline Child maltreatment (0-16y) & $\mathrm{N}(\%)$ & $\mathrm{N}(\%)$ & $\mathrm{N}(\%)$ & $\mathrm{p}_{\text {sex-difference }}^{\mathfrak{f}}$ \\
\hline Neglect (prospective)* & $634(17.2)$ & $574(14.8)$ & $1208(16.0)$ & $<0.01$ \\
\hline Emotional neglect & $429(10.9)$ & 449 (10.9) & $878(10.9)$ & 0.99 \\
\hline Sexual abuse & $18(0.5)$ & $97(2.4)$ & $115(1.4)$ & $<0.01$ \\
\hline Physical abuse & $225(5.7)$ & $224(5.4)$ & $449(5.6)$ & 0.59 \\
\hline Psychological abuse & $314(8.0)$ & $462(11.2)$ & $776(9.6)$ & $<0.01$ \\
\hline Witness abuse & $166(4.2)$ & $297(7.2)$ & $463(5.7)$ & $<0.01$ \\
\hline \multicolumn{5}{|l|}{$\begin{array}{l}\text { Labour market participation, living standards } \\
\text { and social class }(50 y)^{\$}\end{array}$} \\
\hline $\operatorname{LTS}^{\epsilon}$ & $145(3.9)$ & $168(4.7)$ & $313(4.3)$ & 0.10 \\
\hline $\mathrm{NEET}^{\mathscr{C}}$ & $144(3.9)$ & $420(10.9)$ & $564(7.4)$ & $<0.01$ \\
\hline Lack of assets ${ }^{¥}$ & $532(13.5)$ & $566(13.8)$ & $1098(13.7)$ & 0.79 \\
\hline Income-related support ${ }^{\mathrm{K}}$ & $420(13.2)$ & $710(18.0)$ & $1130(15.9)$ & $<0.01$ \\
\hline Financial insecurity $\chi$ & $208(5.4)$ & $239(6.0)$ & $447(5.7)$ & 0.32 \\
\hline Poor qualifications $^{\neq}$ & $1308(33.2)$ & $1150(27.9)$ & $2458(30.4)$ & $<0.01$ \\
\hline Manual social class & $1390(39.0)$ & $794(23.2)$ & $2184(31.3)$ & $<0.01$ \\
\hline \multicolumn{5}{|l|}{ Social mobility to age $50 y$} \\
\hline From class at birth (inter-generational) & & & & $<0.01$ \\
\hline Stable manual & $1105(32.0)$ & $603(18.1)$ & $1708(25.2)$ & \\
\hline Upward from manual class & $1251(36.2)$ & $1715(51.6)$ & $2966(43.8)$ & \\
\hline Stable non-manual & $858(24.9)$ & $835(25.1)$ & $1693(25.0)$ & \\
\hline Downward from non-manual class & $239(6.9)$ & $171(5.1)$ & $410(6.1)$ & \\
\hline From class at age $23 y$ (intra-generational) & & & & $<0.01$ \\
\hline Stable manual & $993(34.1)$ & 313 (10.6) & $1306(22.2)$ & \\
\hline Upward from manual class & $632(21.7)$ & $382(12.9)$ & $1014(17.3)$ & \\
\hline Stable non-manual & $1108(38.1)$ & $1908(64.4)$ & $3016(51.3)$ & \\
\hline Downward from non-manual class & $177(6.1)$ & $361(12.2)$ & $538(9.2)$ & \\
\hline
\end{tabular}

\footnotetext{
$\mathrm{N}$ varies due to missing data

${ }^{\mathrm{x}} \mathrm{p}$-value from $\chi^{2}$-test

*at either $7 \mathrm{y}$ and/or $11 \mathrm{y}$

$\$$ details in ST1

${ }^{\epsilon}$ LTS: long-term sickness absence

${ }^{\mathbb{N}}$ NEET: not in employment, education or training

${ }^{¥}$ Non-home owner

${ }^{K}$ receiving $\geq 1$ targeted benefit or tax credit

$\chi_{\text {reported at } 45 y}$

${ }^{*}<\mathrm{O}$-level (broadly comparable to < grade 10 in the US)
} 
Table 4: OR (95\% CI) for associations between types of child maltreatment and adult outcomes (labour market participation, living standards and social class) in the 1958 birth cohort

\begin{tabular}{|c|c|c|c|c|c|c|c|}
\hline \multirow[b]{2}{*}{ Adult outcome } & & \multirow[t]{2}{*}{ Neglect (prospective) } & \multirow[t]{2}{*}{ Emotional neglect } & \multirow[t]{2}{*}{ Sexual abuse } & \multicolumn{3}{|c|}{ Non-sexual abuse } \\
\hline & & & & & 0 & 1 & $2-3$ \\
\hline \multirow[t]{5}{*}{ LTS* } & Unadjusted $^{\mathfrak{f}}$ & $2.50(1.94,3.22)$ & $1.76(1.30,2.39)$ & $3.51(1.93,6.36)$ & 1 & $2.06(1.47,2.89)$ & $2.77(1.93,3.98)$ \\
\hline & Adjusted $^{¥}$ & $1.69(1.28,2.23)$ & $1.18(0.84,1.65)$ & $1.80(0.95,3.42)$ & 1 & $1.75(1.22,2.51)$ & $2.10(1.40,3.17)$ \\
\hline & $+16 y$ cognition & $1.23(0.92,1.63)$ & & & 1 & $1.87(1.30,2.68)$ & $2.31(1.53,3.51)$ \\
\hline & $+16 y$ mental health & $1.52(1.15,2.02)$ & & & 1 & $1.67(1.17,2.40)$ & $1.93(1.28,2.92)$ \\
\hline & $+16 y$ cognition and mental health & $1.19(0.89,1.58)$ & & & 1 & $1.80(1.25,2.60)$ & $2.18(1.43,3.31)$ \\
\hline \multirow[t]{5}{*}{ NEET $^{\dagger}$} & Unadjusted $^{£}$ & $1.67(1.32,2.13)$ & $1.41(1.09,1.82)$ & $1.87(1.07,3.25)$ & 1 & $1.33(0.99,1.79)$ & $1.62(1.17,2.24)$ \\
\hline & Adjusted $^{¥}$ & $1.43(1.10,1.85)$ & $1.20(0.92,1.58)$ & $1.35(0.75,2.43)$ & 1 & $1.20(0.89,1.63)$ & $1.33(0.93,1.90)$ \\
\hline & + 16y cognition & $1.29(0.99,1.69)$ & & & & & \\
\hline & $+16 y$ mental health & $1.37(1.06,1.78)$ & & & & & \\
\hline & $+16 y$ cognition and mental health & $1.27(0.97,1.67)$ & & & & & \\
\hline \multirow[t]{5}{*}{ Lack of assets } & Unadjusted $^{\mathfrak{f}}$ & $2.27(1.93,2.66)$ & $1.44(1.19,1.73)$ & $2.60(1.72,3.92)$ & 1 & $1.51(1.22,1.87)$ & $1.78(1.40,2.27)$ \\
\hline & Adjusted $^{¥}$ & $1.68(1.42,1.99)$ & $1.13(0.92,1.38)$ & $1.62(1.04,2.53)$ & 1 & $1.31(1.04,1.64)$ & $1.36(1.04,1.78)$ \\
\hline & + 16y cognition & $1.35(1.13,1.61)$ & & $1.49(0.95,2.33)$ & 1 & $1.36(1.08,1.70)$ & $1.44(1.10,1.89)$ \\
\hline & $+16 y$ mental health & $1.55(1.30,1.85)$ & & $1.56(1.00,2.43)$ & 1 & $1.27(1.01,1.59)$ & $1.28(0.97,1.67)$ \\
\hline & $+16 y$ cognition and mental health & $1.31(1.10,1.57)$ & & $1.48(0.94,2.31)$ & 1 & $1.32(1.05,1.66)$ & $1.37(1.04,1.80)$ \\
\hline \multirow[t]{5}{*}{ Income-related support } & Unadjusted $^{f}$ & $1.17(0.97,1.40)$ & $1.19(0.98,1.44)$ & $2.15(1.41,3.27)$ & 1 & $1.34(1.08,1.67)$ & $1.49(1.16,1.91)$ \\
\hline & Adjusted $^{¥}$ & $1.03(0.85,1.24)$ & $1.03(0.84,1.27)$ & $1.75(1.12,2.72)$ & 1 & $1.29(1.03,1.61)$ & $1.32(1.00,1.74)$ \\
\hline & + 16y cognition & & & $1.68(1.07,2.62)$ & 1 & $1.31(1.04,1.64)$ & $1.35(1.03,1.78)$ \\
\hline & $+16 y$ mental health & & & $1.70(1.09,2.66)$ & 1 & $1.26(1.01,1.58)$ & $1.28(0.97,1.69)$ \\
\hline & $+16 y$ cognition and mental health & & & $1.66(1.06,2.59)$ & 1 & $1.29(1.03,1.61)$ & $1.32(1.00,1.74)$ \\
\hline \multirow{5}{*}{ Financial insecurity } & Unadjusted $^{\mathfrak{f}}$ & $1.31(1.02,1.68)$ & $2.37(1.87,3.00)$ & $2.95(1.70,5.13)$ & 1 & $2.42(1.84,3.19)$ & $2.24(1.60,3.14)$ \\
\hline & Adjusted $^{¥}$ & $1.16(0.88,1.54)$ & $1.86(1.43,2.41)$ & $1.86(1.04,3.34)$ & 1 & $2.02(1.51,2.69)$ & $1.56(1.08,2.27)$ \\
\hline & + 16y cognition & & $1.85(1.43,2.40)$ & $1.85(1.03,3.32)$ & 1 & $2.02(1.52,2.70)$ & $1.57(1.08,2.27)$ \\
\hline & $+16 y$ mental health & & $1.84(1.42,2.39)$ & $1.84(1.02,3.30)$ & 1 & $2.00(1.49,2.67)$ & $1.53(1.06,2.22)$ \\
\hline & $+16 y$ cognition and mental health & & $1.84(1.42,2.39)$ & $1.84(1.02,3.30)$ & 1 & $2.00(1.50,2.67)$ & $1.53(1.06,2.23)$ \\
\hline \multirow[t]{5}{*}{ Poor qualifications } & Unadjusted $^{f}$ & $3.67(3.22,4.18)$ & $1.32(1.14,1.53)$ & $2.33(1.61,3.38)$ & 1 & $1.14(0.95,1.35)$ & $1.32(1.07,1.61)$ \\
\hline & Adjusted $^{¥}$ & $2.30(1.99,2.66)$ & $1.11(0.94,1.32)$ & $1.53(1.00,2.34)$ & 1 & $0.90(0.73,1.09)$ & $0.88(0.69,1.12)$ \\
\hline & + 16y cognition & $1.37(1.15,1.63)$ & & $1.27(0.78,2.04)$ & & & \\
\hline & $+16 y$ mental health & $2.07(1.78,2.39)$ & & $1.44(0.93,2.22)$ & & & \\
\hline & $+16 y$ cognition and mental health & $1.32(1.11,1.58)$ & & $1.25(0.77,2.03)$ & & & \\
\hline \multirow[t]{5}{*}{ Manual social class } & Unadjusted $^{f}$ & $2.54(2.22,2.91)$ & $1.26(1.07,1.48)$ & $2.15(1.37,3.36)$ & 1 & $0.97(0.79,1.18)$ & $1.15(0.90,1.45)$ \\
\hline & Adjusted $^{¥}$ & $1.77(1.53,2.06)$ & $1.17(0.97,1.40)$ & $1.80(1.11,2.93)$ & 1 & $0.79(0.64,0.98)$ & $0.82(0.63,1.07)$ \\
\hline & + 16y cognition & $1.26(1.08,1.48)$ & & $1.68(1.01,2.79)$ & & & \\
\hline & +16 y mental health & $1.64(1.41,1.91)$ & & $1.78(1.09,2.89)$ & & & \\
\hline & $+16 y$ cognition and mental health & $1.23(1.05,1.45)$ & & $1.68(1.01,2.79)$ & & & \\
\hline
\end{tabular}

*LTS: long-term sickness absence (baseline = employed, in education or training).

${ }^{7}$ NEET: not in employment, education or training (baseline = employed, in education or training).

${ }^{\mathfrak{E}}$ Results are presented for sexes combined as there was no evidence of differences in effect (i.e. $p$-value for maltreatment*sex $\geq 0.06$ ); all associations are sex adjusted

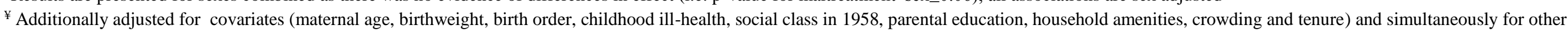
types of child maltreatment

${ }^{\chi}$ Score for cumulative experience of physical, physiological or witnessing abuse $(0=86.8 ; 1=7.9 \% ; 2-3=5.5 \%)$ 
Table 5: OR (95\% CI) for associations between types of child maltreatment and (inter- and intra-generational) social mobility in the 1958 birth cohort

\begin{tabular}{|c|c|c|c|c|c|c|}
\hline & Neglect (prospective) & Emotional neglect & Sexual abuse & \multicolumn{3}{|c|}{ Non-sexual abuse ${ }^{\chi}$} \\
\hline Inter-generational 0-50y & & & & 0 & 1 & $2-3$ \\
\hline Upward vs stable manual & $0.45(0.39,0.53)$ & $0.87(0.71,1.06)$ & $0.50(0.30,0.85)$ & Ref & $1.24(0.98,1.57)$ & $1.14(0.86,1.53)$ \\
\hline Downward vs stable non-manual & $2.31(1.56,3.41)$ & $1.15(0.77,1.72)$ & $1.85(0.57,6.04)$ & Ref & $0.93(0.59,1.48)$ & $0.95(0.53,1.70)$ \\
\hline Intra-generational 23-50y & & & & & & \\
\hline Upward vs stable manual & $0.61(0.50,0.74)$ & $0.96(0.75,1.24)$ & $0.47(0.22,1.01)$ & Ref & $1.46(1.08,1.98)$ & $1.30(0.87,1.94)$ \\
\hline Downward vs stable non-manual & $2.11(1.63,2.74)$ & $1.16(0.85,1.58)$ & $1.49(0.71,3.13)$ & Ref & $1.11(0.81,1.53)$ & $1.15(0.76,1.74)$ \\
\hline
\end{tabular}

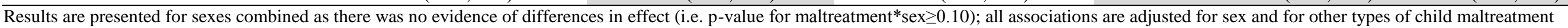

$\chi$ Score for cumulative experience of physical, physiological or witnessing abuse 